\title{
Comparison between dexmedetomidine and propofol for sedation during mechanically ventilated patients after major intraabdominal surgeries: An observational study
}

\author{
Neeraj Kumar ${ }^{1, *}$, Amarjeet Kumar², Ashish Kumar ${ }^{3}$, Mumtaz Hussain ${ }^{4}$, Anil Kumar ${ }^{5}$ \\ ${ }^{1,2,3}$ Senior Resident, ${ }^{4}$ Associte Professor, ${ }^{5}$ Assistant Professor, ${ }^{1,2,5}$ Dept. of Trauma \& Emergency, ${ }^{3,4}$ Dept. of Anaesthesiology, \\ $\mathbf{1 , 2 , 3}^{\mathbf{1}}$ All India Institute of Medical Sciences, Patna, Bihar, ${ }^{4}$ Indira Gandhi Institute of Medical Sciences, Patna, Bihar, India
}

*Corresponding Author:

Email: neeraj.jlnmc@gmail.com

Received: $15^{\text {th }}$ May, 2017

Accepted: $15^{\text {th }}$ December, 2017

\begin{abstract}
Introduction: Major complex intraabdominal surgeries which have prolonged intraoperative surgical duration and wide hemodynamic fluctuations so they required an elective mechanical ventilation in view of large fluid shift and massive blood loss. So such large group of patients for providing conscious sedation two most popular agents dexmedetomidine and propofol are being used because their mechanisms of action and pharmacokinetic properties are different.

Aims and Objectives: Primary aim of our study is to assess the duration of mechanical ventilation in both study group (D or P) following major intraabdominal surgery. The secondary aim was to evaluate total duration of intensive care unit as well as hospital stay, incidence of delirium and any additional sedative agent

Materials and Methods: All patients on arrival to the ICU and after fulfilling the inclusion and exclusion criteria following completion of major intraabdominal surgeries they were allocated, randomly using sealed envelopes techniques into two groups each comprising of 15 patients, to receive intravenous infusions of either dexmedetomidine or propofol and plan for elective mechanical ventilation.

Statistical analysis: All data's was statistically analysed using Minitab® 16 (Minitab, Inc., State College, PA) software.

Results: In our study variables like demographic profile, baseline hemodynamics and ASA status were comparable in both the study groups. Our study results showed that total duration of mechanical ventilation was much earlier in the dexmedetomidine group compared to propofol $(7.62$ hours vs. 11.23 hours, $\mathrm{P}<0.05)$ and found to be statistically significant $(\mathrm{P}<0.05)$. Our study results also suggested that on comparing duration of stay in intensive care unit as well as in hospital, the dexmedetomidine group has much lesser stay in ICU as well as in hospital compared to propofol group and it was statistically not significant (P > 0.05). The incidence of delirium were more in patient receiving propofol group $(6.6 \%$ vs. $20 \%, \mathrm{P}=0.346)$.

Conclusion: This study concluded that for any complex major intraabdominal surgeries dexmedetomidine has significant reduction in time on mechanical ventilation but no significant difference was seen in terms of incidence of delirium, duration of ICU or hospital stay and mortality.
\end{abstract}

Keywords: Major abdominal surgery, Sedation, Dexmedetomidine, Propofol.

\section{Introduction}

All patient who underwent a major complex intraabdominal surgeries requires a mechanical ventilation in presence of sedatives and analgesics to facilitate their proper care in terms of airway protection and hemodynamic stability. ${ }^{34}$ If a protocol-based strategies is applied to an intensive care unit it would not only reduce the cost but also variations pertaining to intensive care unit, leading to improve morbidity and mortality among critically ill patients. ${ }^{35}$ There are various sedative drugs that are available in the market with distinct drug profiles. The main goal of these drugs is to provide sedation in mechanically ventilated patients and to keep all patients quiet or restful and more important to prevent any ventilator dysynchronisation on elective ventilation. ${ }^{1,2}$ So for improved outcome an adequate level of analgesia and sedation is necessary. An ideal sedative should be easy to administer with rapid onset and offset, they have better cardio-respiratory stability and should be devoid of any toxicity. Inadequate sedative techniques may adversely affect morbidity and even deaths in intensive care unit (ICU) ${ }^{1,2}$ and the search for the ideal sedative agent is still in process. The most commonly used drugs are midazolam, propofol and fentanyl. All of these drugs cause respiratory depression. ${ }^{1,2}$ Propofol is a very short acting non-opioid sedative-hypnotic agent with rapid onset and offset but with narrow therapeutic index leading to risk of progression into deep sedation.

As far as dexmedetomidine is concerned it is a $\alpha_{2}$ adrenergic receptor agonist with central acting properties and for first 24 hours of ICU admission it has been approved for providing sedation in mechanically ventilated patients. ${ }^{8}$ It has been a popular choice as sedative over benzodiazepines both for intubated and non-intubated patients admitted to ICU because of its analgesic properties, conscious sedation, lack of respiratory depression and its sympatholytic effect and its attractive pharmacologic profile along with a very impressive safety margin, has made it an effective agent for anaesthesiologists and intensivist. ${ }^{3}$ 
Some studies also concluded that it is a very effective drugs for sedation and for reducing the incidence of delirium and reduced consumption of opioids because of its analgesic properties. ${ }^{9-18}$

The major concern of this drug is that on rapid intravenous administration it causes hypertension but hypotension (24\%-54\%) followed by bradycardia (5\%$14 \%$ ) are common side effects. Propofol is a 2, 6 diisopropyl phenol compound commonly used as sedative-hypnotic agent for providing day care anaesthesia as well as for induction and maintenance anaesthesia. ${ }^{20}$ This drug has rapid onset, shorter duration of action, and relatively cheap on compared to other inducing agent, but in case of cardiovascular patients it should be cautiously used owing to its severe adverse effects. ${ }^{1,2}$ Even at standard doses propofol causes hemodynamic instability, like bradycardia and hypotension, so it has been shown to be a use-limiting side effect. ${ }^{21-24}$ We know that prolonged use of propofol may lead to hypertriglyceridemia because of presence of fat-based emulsion. ${ }^{1,2,25,26}$ We followed a nursesdriven protocol for assessment of Richmond Agitation Sedation (RASS) score but goal was set by the concerned intensivist. In our study nursing staff titrated the sedative agent dose as per protocol and they only targeted the set RASS score. We followed standard ICU sedation protocol for every enrolled patients. All of our study group patients have been scheduled for daily sedation free period at 8:00 AM in the morning.

\section{Materials and Methods}

Patients and study Design: After getting approval from Institutional Ethical committee, 50 patients aged between 18-60 years, of both sex, having American Society of Anaesthesiologist (ASA) grade I \& II scheduled for postoperative elective mechanical ventilation after complex major intraabdominal surgeries between study period of 2013 and 2015 were included in this study. We conducted this prospective randomised study at various medical colleges of Bihar, India. All patients on arrival to the ICU and after fulfilling the inclusion criteria following completion of major intraabdominal surgeries 30 patients were allocated, randomly using sealed envelopes techniques into two groups each comprising of 15 patients, to receive intravenous infusions of either dexmedetomidine or propofol and plan for elective mechanical ventilation. If analgesia was required at any point of time morphine was used at a bolus dose of $0.05 \mathrm{mg} / \mathrm{kg}$. We compared various parameters like RAAS and CAM for sedation score, hemodynamic parameters, infusion doses of both sedative drugs and total length of stay at either at ICU or hospital. In patients randomized to dexmedetomidine group (Group D) they received a dose $1 \mu \mathrm{g} / \mathrm{kg}$ was used as initial dose followed by $0.2-0.7 \mu \mathrm{g} / \mathrm{kg} /$ hour for 10 minutes via infusion pump. In patients randomized to propofol group (Group P), received an initial loading dose of propofol $(75 \mu \mathrm{g} / \mathrm{kg} / \mathrm{min})$ was infused for 10 minutes followed by maintenance dose of $12.5-75 \mu \mathrm{g}$ $/ \mathrm{kg} / \mathrm{min}$ via infusion pump. The primary aim of our study is to compare the duration of mechanical ventilation in both study group (D or $\mathrm{P}$ ) following major intraabdominal surgery. The secondary aim was to evaluate total duration of intensive care unit as well as hospital stay, incidence of delirium and any additional sedative agent in the form of lorazepam or dexmedetomidine groups of patients receiving propofol and vice versa was documented. We also monitored RASS score and Confusion Assessment Method-ICU (CAM-ICU) along with in hospital mortality in both group of patients.

Exclusion criteria: Limited to any suspected allergy to dexmedetomidine or propofol, severe hepatic or renal disease., chronic use of $\alpha$-agonist, requirement of muscle relaxant, other than for intubation (succinylcholine), pregnancy or lactation, severe pulmonary or cardiac disorder, age $<18$ year, history of sleep apnoea, or body weight $50 \%$ greater than ideal body weight, patient receiving total parenteral nutrition.

\section{Statistical analysis}

Our study results was expressed as mean \pm standard deviation or as a percentage or number values. We compared all continuous variables using the Student t-test and all our categorical data was compared using chi square without Yates correction with $2 \times 2$ contingency table and Fisher exact test. For analysis of all datas a statistical software Minitab ${ }^{\circledR} 16$ (Minitab, Inc., State College, PA) was used. From a previous work $^{6,7}$ and to have a power of $80 \%$ to detect a $50 \%$ reduction in analgesic requirement and a $20 \%$ reduction in heart rate at a significance level of 5 we have a sample size consisting of forty patients in both groups including drop outs. All P-values were considered statistically significant only if $\mathrm{p}<0.05$.

\section{Results}

Out of 50 enrolled patients, 30 patients successfully completed the study, 20 patients excluded from study as not fulfilling the inclusion criteria as shown in consort diagram [Chart 1]. In our study following variables like demographic profile, baseline hemodynamics, ASA status were comparable in both the study groups [Table V] and various types of complex major intraabdominal surgeries distribution included in our study was shown as pie chart [Fig. 1]. Then they were randomised to receive infusion of dexmedetomidine and propofol. Our study results showed that total duration of mechanical ventilation is lesser in dexmedetomidine group compared to propofol (7.62 hours vs. 11.23 hours, $\mathrm{P}=<0.05$ ) and found to be statistically significant $(\mathrm{P}<0.05)$ [Table I]. Our study results also suggested that on comparing duration of stay in intensive care unit as well as in hospital, the dexmedetomidine group has much lesser stay than 
propofol group (2.5 days vs.3.8 days, $\mathrm{P}>0.05)$ similarly duration of hospital stay result was (8.6 days vs. 11.8 days, $\mathrm{P}>0.05)$ and both are not statistically significant [Table II]. The incidence of delirium was more in patient receiving propofol $(6.6 \%$ vs. $20 \%, \mathrm{P}=$ $0.346)$. Our study also showed that patient receiving dexmedetomidine have lesser requirement of second sedative for providing sedation as compared to propofol receiving group and (13\% vs. $20 \%, \mathrm{P}=$ 0.678) was not significant [Table IV]. Finally our studies showed no significant difference on comparing various parameters like incidence of delirium, ICU \& Hospital length of stay or mortality between both study groups. Only two patients out of total three $(66.6 \%)$ in propofol study group received lorazepam as additional sedatives. [Table IV]. In our study group RASS score was assessed in each and every patients but were not included in our study as we used more than one sedatives with opioids as per requirement. In the dexmedetomidine group we observed $93 \%$ of patients have positive CAM ICU score as compared to $80 \%$ in the propofol group and was statistically insignificant $(\mathrm{P}$ $>0.05$ ). In our study we calculated and compared the maximum as well as average dose of infusion that was consumed for both dexmedetomidine as well as propofol which was about $0.536 \pm 0.23 \mathrm{mcg} / \mathrm{kg} / \mathrm{hr}$ and $0.362 \pm 0.16 \mathrm{mcg} / \mathrm{kg} / \mathrm{hr}$ and for propofol it was $29.18 \pm 8.73 \mathrm{mcg} / \mathrm{kg} / \mathrm{hr}$ and $23.63 \pm 7.54 \mathrm{mcg} / \mathrm{kg} / \mathrm{hr}$. [Table III] However no mortality was observed in both the groups. [Table IV]

\section{Chart 1: Flow chart of enrolled patients in both study groups (D or P)}

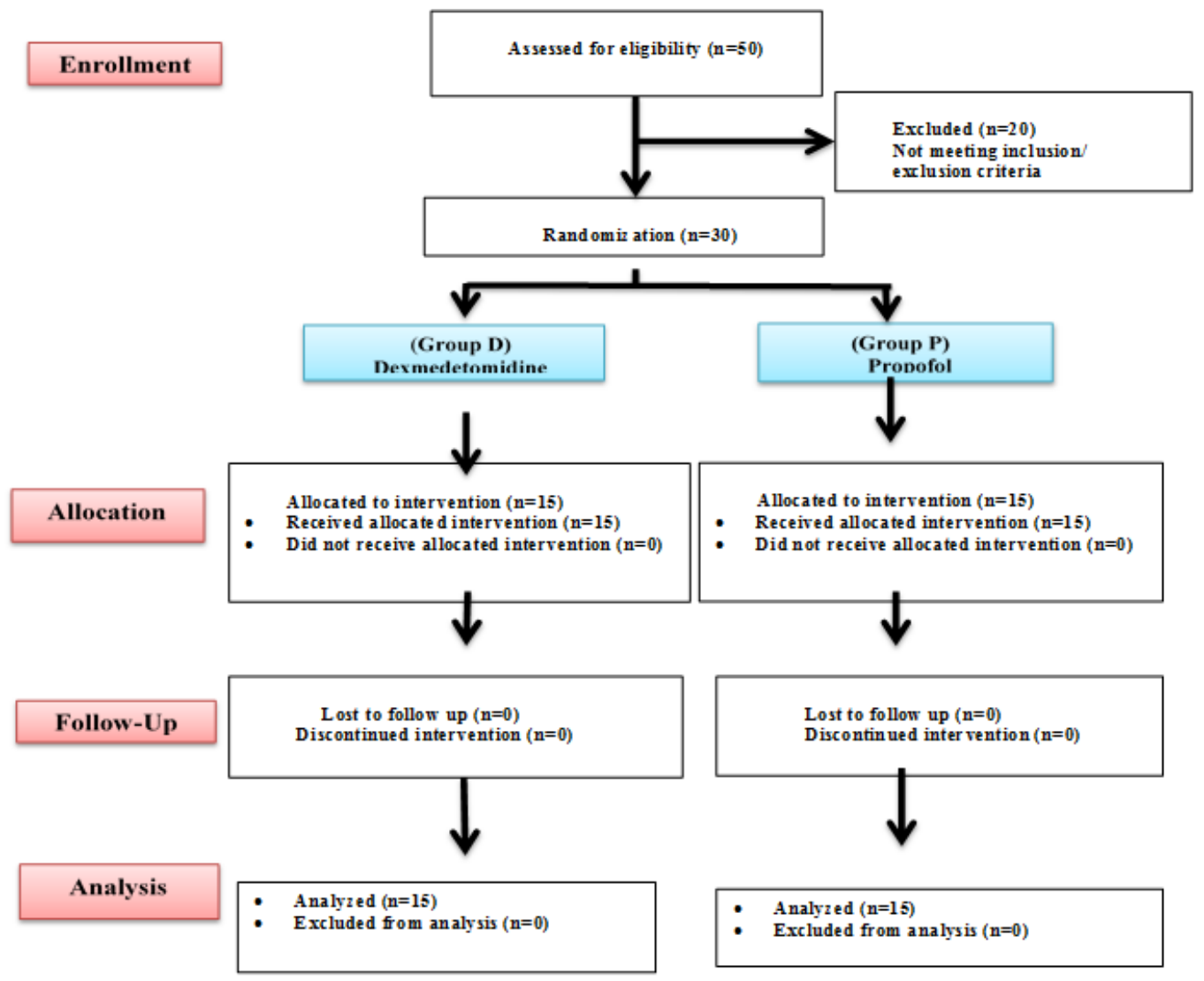

Table I: (Mechanical ventilation duration)

\begin{tabular}{|l|l|l|l|}
\hline Parameter & $\begin{array}{l}\text { Group D } \\
(\mathbf{n = 1 5})\end{array}$ & $\begin{array}{l}\text { Group P } \\
(\mathbf{n = 1 5})\end{array}$ & P value \\
\hline $\begin{array}{l}\text { Mechanical ventilation } \\
\text { duration (hours) }\end{array}$ & $7.62 \pm 2.93$ & $11.23 \pm 5.24$ & $\begin{array}{l}0.027 \\
(\mathrm{p}<0.05)\end{array}$ \\
\hline
\end{tabular}


Table II: (Length of stay)

\begin{tabular}{|l|l|l|l|}
\hline Parameter & $\begin{array}{l}\text { Group } \\
\text { D (n=15) }\end{array}$ & $\begin{array}{l}\text { Group P } \\
\text { (n=15) }\end{array}$ & P value \\
\hline $\begin{array}{l}\text { Length of stay in } \\
\text { ICU (days) }\end{array}$ & $2.5 \pm 1.35$ & $3.8 \pm 2.15$ & 0.057 \\
\hline $\begin{array}{l}\text { Length of stay in } \\
\text { Hospital (days) }\end{array}$ & $8.6 \pm 3.39$ & $11.8 \pm 5.82$ & 0.076 \\
\hline
\end{tabular}

Table III: (Infusion doses)

\begin{tabular}{|l|l|l|l|}
\hline Parameter & $\begin{array}{l}\text { Group D } \\
(\mathbf{n = 1 5})\end{array}$ & $\begin{array}{l}\text { Group P } \\
(\mathbf{n = 1 5})\end{array}$ & P value \\
\hline $\begin{array}{l}\text { Propofol dosing } \\
(\mathrm{mcg} / \mathrm{kg} / \mathrm{min})\end{array}$ & \multicolumn{3}{|l|}{} \\
\hline Average dose & & $23.63 \pm 7.54$ & \\
\hline Maximum Dose & & $29.18 \pm 8.73$ & \\
\hline $\begin{array}{l}\text { Dexmedetomidine } \\
\text { dosing (mcg/kg/hr) }\end{array}$ & & & \\
\hline Average dose & $0.362 \pm 0.16$ & & \\
\hline Maximum Dose & $0.536 \pm 0.23$ & & \\
\hline
\end{tabular}

Table IV: (Incidence of delirium/Second sedative agent/Hospital deaths)

\begin{tabular}{|l|l|l|l|}
\hline Parameter & $\begin{array}{l}\text { Group D } \\
(\mathbf{n = 1 5})\end{array}$ & $\begin{array}{l}\text { Group P } \\
(\mathbf{n = 1 5})\end{array}$ & P value \\
\hline $\begin{array}{l}\text { Incidence delirium } \\
\text { (CAM-ICU)* }\end{array}$ & $1(6.6)$ & $3(20)$ & 0.346 \\
\hline $\begin{array}{l}\text { Addition of second } \\
\text { sedative agent* }\end{array}$ & $2(13.3)$ & $3(20)$ & 0.678 \\
\hline Dexmedetomidine & NA & $1(33.3)$ & NA \\
\hline Propofol & $2(100)$ & NA & NA \\
\hline Lorazepam number of & $0(0)$ & $2(66.6)$ & N/A \\
\hline $\begin{array}{l}\text { Total num } \\
\text { Hospital death }\end{array}$ & $0(0)$ & 0 \\
\hline
\end{tabular}

*Chi square without Yates correction, two tailed $\mathrm{P}$ value, $2 \times 2$ contingency table

Table V: Demographic variables

\begin{tabular}{|l|l|l|l|}
\hline $\begin{array}{l}\text { Demographic } \\
\text { variables }\end{array}$ & $\begin{array}{l}\text { Group D } \\
(\mathbf{n = 1 5})\end{array}$ & $\begin{array}{l}\text { Group P } \\
(\mathbf{n = 1 5})\end{array}$ & $\begin{array}{l}\text { P } \\
\text { value }\end{array}$ \\
\hline Mean \pm SD & \multicolumn{3}{|l|}{} \\
\hline Age (years) & $63 \pm 14.1$ & $68 \pm 11.2$ & 0.0106 \\
\hline Weight $(\mathrm{kg})$ & $81.38 \pm 12.04$ & $84.23 \pm 19.35$ & 0.4053 \\
\hline Height $(\mathrm{cm})$ & $174.15 \pm 4.30$ & $171.96 \pm 10.30$ & 0.2274 \\
\hline No. patients (\%) & \multicolumn{3}{|l}{} \\
\hline Gender* & \multicolumn{3}{|l}{} \\
\hline Male & 13 & 0.271 \\
\hline Female & 0201 & 0.333 \\
\hline ASA status (I/II)* & $12 / 3$ & $11 / 4$ &
\end{tabular}

*Chi square without Yates correction, one tailed $\mathrm{P}$ value, $2 \times 2$ contingency table 


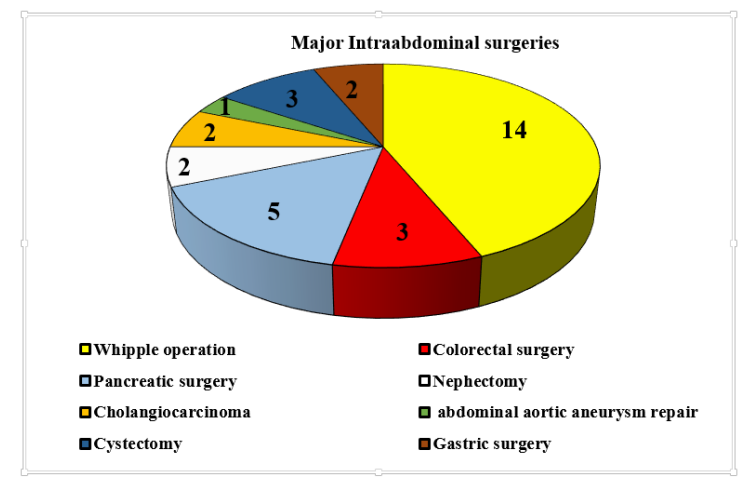

Fig. 1: Pie chart showing total number of major intraabdominal surgeries $(n=30)$

\section{Discussion}

There are large number of sedative hypnotic agents used for providing sedation and analgesia in patients undergoing elective mechanical ventilation. On searching various literature we found few studies that have directly compared dexmedetomidine and propofol for sedation efficacy and overall outcomes in patients undergoing major intra-abdominal surgery. An intensive care environment is very stressful for the patient who experience anxiety, pain and sedation. In our study we observed patient receiving dexmedetomidine-based sedation (7.62 hours) have statistically significant reduction $(\mathrm{P}<0.05)$ in time total duration of mechanical ventilation as compared to propofol (11.23 hours). Due to shorter duration of mechanical ventilation resulted in decrease incidence of ventilator associated pneumonia and delirium. No significant difference were observed on comparing secondary objective. Around 10 to $20 \%$ of patients required both sedative agent as well as another long acting sedative agent lorazepam. The study group which received more than one agent for sedation have worse overall outcome mainly due to increase duration of mechanical ventilation. If ICU delirium is present it has huge impact on increase in length of stay to ICU as well as hospital and overall hospitalization cost. ${ }^{28-31}$ Some of the recent literature has focused on awareness and screening of delirium especially by a healthcare providers. ${ }^{32}$ We performed screening for delirium in all patients using CAM-ICU method a minimum of one time during their total ICU stay. We observed that a delirium is present in $3 \%$ patients of dexmedetomidine receiving and $20 \%$ in propofol receiving patients. Our study concluded that if both group of patients receiving an additional sedation may have worst outcome with increased risk of delirium. Some patients are more CAM-ICU positive on receiving both dexmedetomidine and propofol infusion simultaneously as compared to single agent for sedation either dexmedetomidine or propofol. Our study showed better improvement of patient outcome with lesser dependence on mechanical ventilation due to a systematic methods and validated sedation protocol ${ }^{[5-7]}$ In our study we achieved a favourable sedation in our study groups because we followed regular analysis of sedation protocols, protocol

for daily sedation free period, close monitoring of hemodynamic parameters and management of all adverse events.

\section{Limitations of our study}

No study is without limitations similarly our study has a few limitations in the form of very small sample size a major limitation, no documentation of RAAS score data to our study group as level of sedation may be altered in view of prescribing some additional medication like opioids and some benzodiazepines and lastly patients and surgeon satisfaction score was not checked, which may have altered a patient's level of sedation and affected their time on mechanical ventilation and other outcomes.

\section{Conclusion}

Our study concluded that in a complex major intraabdominal surgeries use of dexmedetomidine as compared to propofol infusion has significantly greater impact on decreasing mechanical ventilation duration but on comparing incidence of delirium, number of ICU or hospital stay (in days) and mortality were statistically not significant.

\section{References}

1. Jacobi J, Fraser GL, Coursin DB, Riker RR, Fontaine D, Wittbrodt ET, et al. Clinical practice guidelines for the sustained use of sedatives and analgesics in the critically ill adult. Crit Care Med. 2002;30:119-41.

2. Devlin JW, Roberts RJ. Pharmacology of commonly used analgesics and sedatives in the ICU: benzodiazepines propofol, and opioids. Crit Care Clinics. 2009;25(3):4319.

3. Myles PS, Daly DJ, Djalani G, Lee A, Cheng DCH. A systematic review of the safety and effectiveness of fasttrack cardiac anesthesia. Anesthesiology. 2003;99:982-7.

4. Cheng DC. Fast track cardiac surgery pathways: Early extubation, process of care, and cost containment. Anesthesiology. 1998; 88(6):1429-33.

5. Schweickert WD, Kress JP. Strategies to optimize analgesia and sedation. Critical Care. 2008;12(3)

6. Sessler CN, Pedram S. Protocolized and target-based sedation and analgesia in the ICU. Anesthesiol Clin. 2011;29(4):625-50. 
7. Marshall J, Finn CA, Theodore AC. Impact of a clinical pharmacist-enforced intensive care unit sedation protocol on duration of mechanical ventilation and hospital stay. Crit Care Med. 2008; 36(2):427-33.

8. Precedex [package insert]. Lake Forest, IL: Hospira, Inc; 2010.

9. Martin E, Ramsay G, Mantz J, Sum-Ping ST. The role of the alpha2-adrenocepter agonist dexmedetomidine in postsurgical sedation in the intensive care unit. $\mathbf{J}$ Intensive Care Med. 2003;18:29-41.

10. Anger KE, Szumita PM, Baroletti SA, Labreche MJ, Fanikos J. Evaluation of dexmedetomidine versus propofol-based sedation therapy in mechanically ventilated cardiac surgery patients at a tertiary academic medical center. Crit Pathways in Cardiol. 2010;9:221-6.

11. Herr DL, John Sum-Ping ST, England M. ICU sedation after coronary bypass graft surgery: dexmedetomidinebased versus propofol-based sedation regimens. Journal Cardiothor Vasc Anesth. 2003;17(5):576-84.. [PubMed]

12. Pandharipande PP, Pun BT, Herr DL, Maze M, Girard TD, Miller RR, et al. Effect of sedation with dexmedetomidine vs. lorazepam on acute brain dysfunction in mechanically ventilated patients: the MENDS randomized controlled trial. JAMA. 2007;298(22):2644-53. [PubMed]

13. Riker RR, Shehabi Y, Bokesch PM, Ceraso D, Wisemandle W, Koura F, et al. Dexmedetomidine vs. midazolam for sedation of critically ill patients. JAMA. 2009;301(5):489-99. [PubMed]

14. Devabhakthuni S, Pajoumand M, Williams C, Kufera JA, Watson K, Stein DM. Evaluation of dexmedetomidine: safety and clinical outcomes in critically ill trauma patients. J Trauma. 2011;71(5):1164-71. [PubMed]

15. Szumita PM, Baroletti SA, Anger KE, Wechsler ME Sedation and analgesia in the intensive care unit: Evaluating the role of dexmedetomidine. Am J HealthSyst Pharm; 64:37-44.[PubMed]

16. Barletta JF, Miedema SL, Wiseman D, Heiser JC, McAllen KJ. Impact of dexmedetomidine on analgesic requirements in patients after cardiac surgery in a fasttrack recovery room setting. Pharmacotherapy. 2009;29(12):1427-32. [PubMed]

17. Reichert MG, Jones WA, Royster RL, Slaughter TF, Kon ND, Kincaid EH. Effect of a dexmedetomidine substitution during a nationwide shortage in patients undergoing coronary artery bypass graft surgery. Pharmacotherapy. 2011;31(7):673-77.[PubMed]

18. Gerlach AT, Murphy CV, Dasta JF. An updated focused review of dexmedetomidine in adults. Ann Pharmacother. 2009;43:2064-74. [PubMed]

19. Dasta JF, Kane-Gill SL, Pencina M, Shehabi Y, Bokesch $\mathrm{PM}$, Wisemandle $\mathrm{W}$, et al. A cost-minimization analysis of dexmedetomidine compared with midazolam for longterm sedation in the intensive care unit. Crit Care Med. 2010;38(2):497-503. [PubMed]
20. Diprivan [package insert]. Wilmington DE: AstraZeneca Pharmaceuticals LP;2005.

21. Roberts RJ, Barletta JF, Fong JF, Schumaker G, Kuper PJ, Papadopoulos S, et al. Incidence of propofol-related infusions syndrome in critically ill adults: a prospective, multicenter study. Critical Care. 2009;13 [PMC free article] [PubMed]

22. Fodale V, La Monaca E. Propofol infusion syndrome: an overview of a perplexing disease. Drug Saf. 2008;31(4):293-303. [PubMed]

23. Corbett SM, Montoya ID, Moore FA. Propofol-related infusion syndrome in intensive care patients. Pharmacotherapy. 2008;28(2):250-8.[PubMed]

24. Marik PE. Propofol: therapeutic indications and sideeffects. Curr Pharm Des. 2004;10(29):3639-49. [PubMed]

25. Devlin JW, Lau AK, Tanios MA. Propofol-associated hypertriglyceridemia and pancreatitis in the intensive care unit: an analysis of frequency and risk factors. Pharmacotherapy. 2005;25(10):1348-52. [PubMed]

26. Gottschling S, Larsen R, Meyer S, Graf N, Reinhard H. Acute pancreatitis induced by short-term propofol administration. Paediatr Anaesth. 2005;15(11):10068.[PubMed]

27. Elixhauser A, Steiner C, Harris DR, Coffey RM. Comorbidity measures for use with administrative data. Med Care. 1998;36:8-27. [PubMed]

28. Milbrandt EB, Deppen S, Harrison PL, Shintani AK, Speroff T, Stiles RA, et al. Costs associated with delirium in mechanically ventilated patients. Crit Care Med. 2004;32(4):955-62. [PubMed]

29. Lim SM, Liu CY, Wang CH, Lin HC, Huang CD, Huang PY, et al. The impact of delirium on the survival of mechanically ventilated patients. Crit Care Med. 2004;32(11):2254-59. [PubMed]

30. Shehabi Y, Riker RR, Bokesch PM, Widemandle W, Shintani A, Ely EW. Delirium duration and mortality in lightly sedated mechanically ventilated intensive care patients. Crit Care Med. 2010;38(12):2311-18.

31. Ely EW, Shintani A, Truman B, Speroff T, Gordon SM, Harrell FE, et al. Delirium as a predictor of mortality in mechanically ventilated patients in the intensive care unit. JAMA. 2004;291(14):1753-62.

32. Devlin JW, Fong JJ, Howard EP, Skrobik Y, McCoy N, Yasuda C, Marshall J. Assessment of delirium in the intensive care unit: nursing practices and perceptions. Am J Crit Care. 2008;17(6):555-65.

33. Coursin DB, Coursin DB, Maccioli GA. Dexmedetomidine. Curr Opin Crit Care 2001;7:221-6.

34. 35. Holcomb BW, Wheeler AP, Ely EW: New ways to reduce unnecessary variation and improve outcomes in the intensive care unit. Curr Opin Crit Care 2001;7(4):304-11. 